Article

\title{
How to Improve Government Openness for Sustainable Development: The Interaction of Four Factors in African Countries
}

\author{
Eun G. Park (D)
}

Citation: Park, E.G. How to Improve Government Openness for Sustainable Development: The Interaction of Four Factors in African Countries. Sustainability 2021, 13, 8000. https://doi.org/10.3390/ su13148000

Academic Editor: João Leitão

Received: 9 June 2021

Accepted: 14 July 2021

Published: 17 July 2021

Publisher's Note: MDPI stays neutral with regard to jurisdictional claims in published maps and institutional affiliations.

Copyright: (C) 2021 by the author. Licensee MDPI, Basel, Switzerland. This article is an open access article distributed under the terms and conditions of the Creative Commons Attribution (CC BY) license (https:// creativecommons.org/licenses/by/ $4.0 /)$.
Department of Library and Information Science, Kyonggi University, Suwon 16227, Korea; eunpark@kgu.ac.kr; Tel.: +82-31-249-9335

\begin{abstract}
The objectives of this study are to: estimate African countries' Government Openness Index (AGOI) to see the updated progress of open government in those countries, examine which areas African countries should further improve for sustainable development, and compare the performance of the Open Government Partnership (OGP) member countries to that of non-OGP countries in forming AGOI. This study developed the AGOI with 32 selected countries and four factors (ACC (accountability), TRA (transparency), CPF (citizen participation and freedom) and ICT (information and communication technology)) for the period of 2006-2019. The results show that African countries have continuously increased the values of AGOI for the period. ACC has barely changed, but TRA has increased slightly. Both CPF and ICT have increased at higher growth rates during the period. The OGP group reached much better scores than their non-OGP counterparts, with positive differences in AGOI, ICT, CPF, and TRA, except ACC. The results of this study suggest that the constantly increasing $\mathrm{CPF}$ and ICT levels in countries that have similar conditions as African countries should be further improved to function well enough to build accountability and transparency. It is also recommended that countries join the OGP in order to move towards improving government openness and creating sustainable development.
\end{abstract}

Keywords: African countries' Government Openness Index; AGOI; open government; Open Government Partnership; Africa

\section{Introduction and Context of the Study}

As the open government movement has been a major global concern in recent years, the way in which open government influences the sustainable development of countries has become an important issue. Since the Open Government Partnership (OGP), a central international body, was founded in 2011 by eight countries (i.e., Brazil, Indonesia, Mexico, Norway, the Philippines, South Africa, the United Kingdom and the United States), the OGP has currently grown to 78 national members and 56 local jurisdiction members. Member countries have made over 3100 commitments to making their governments more open and accountable [1]. To move towards improving the degree of government openness, African countries have also made noteworthy efforts and achievements. As of March 2021, fifteen African countries have joined the OGP; as a part of the requirements to join, they have made action plans committing to opening government tenets and reforms, such as bringing about the development of an openness in governance, legislature and laws, and the rights of citizens.

To increase an awareness of open government in African countries, some governments have hosted conferences. In 2013, the Africa Freedom of Information Centre organized a conference for thirty civil society organizations to share knowledge and experience related to open government from the countries that first joined the OGP (e.g., Ghana, Kenya, Liberia, South Africa and Tanzania [2]). Ranchod [3] interviewed key players from those five countries and Malawi, which had implemented OGP initiatives. She 
found that the major developments of these countries were identifying the roles of civil society organizations, creating an awareness of open government and promoting Access to Information acts.

In 2016, Burkina Faso's National Agency hosted the first Francophone African Conference on Open Data and Open Government and brought representatives from 22 Frenchspeaking countries to share their commitment to open government initiatives and to promote ICT (information and communication technology) [4]. At this conference, the countries agreed that the principles of open government are key to sustainable social and economic development through the free use of public data. It is beneficial to see that certain African countries have experienced some level of reduction in corruption. Chiviru [5] reported that Cameroon's Fako Division of Buea community was able to save about 5 million XAF (USD 50,500) for a school construction project after the Ministry of Public Contracts implemented open contracting. The Nigeria Extractive Industries Transparency Initiative, a partnership between government and civil society, was able to recover USD 2.4 billion from oil corruption [5]. In 2017, the Africa Open Data Conference was held to host and share various open data groups from African countries [6]. The Code for Africa initiated the largest public OpenAFRICA repository [7], allowing citizens to upload and access open datasets across Africa. The government of Kenya launched the Kenya Open Data Initiative (KODI) [8] portals, which allowed citizens to access government data about the government census, expenditures, and public services.

Regardless of these efforts, the United Nations Economic Commission for Africa (UN ECA) [9] identified that African countries are faced with several challenges in progressing open government activities. Africans seem to prioritize economic development above information governance issues; therefore, core open government indicators may not matter to average African citizens as much as concerns relating to income generation, employment and personal development. As Ranchod [3] addressed, most African countries have limited knowledge of open government in both the national levels and organized civil society, since poor information culture is another impediment: information in the public sector is usually inaccessible. Public officials do not understand their obligation to provide services and public goods and information. As such, laws and policies to open up the information space in African countries may not be effective. In addition, because of poor infrastructure, citizens do not have access to government information either, as they are not used to putting demands on revealing information about their governments as a result of their limited capacity to use information technologies [9].

Relevant studies on African countries' government openness largely deal with the following topics: (1) e-government [10,11], (2) freedom of information access [12-15], and (3) open data initiatives in Africa [16-18]. For example, Adu et al. [10] investigated the implementation progresses of electronic government in Ghana and found that although e-government resources are available and appropriately used to facilitate the activities of government ministries and agencies, public sector organizations are still faced with infrastructure, economic and legal challenges.

The studies of the 2nd group investigated Freedom of Information Act (FOIA) or Access to Information Act in Ghana [12], Nigeria [13], South Africa [19], Sierra Leone [14] and Liberia [15] and examined the acts' impacts on government openness. These studies agreed that the implementation of the acts is unsatisfactory, or, despite implementing FOIA, corrupt practices continue to flourish. As Svärd [15] also remarked, when the acts are not implemented satisfactorily in African countries, public information or records are instead used to exercise control over citizens by governments and other political institutions; government transparency in Africa is still poor.

The studies of the 3rd group of governments describe open data usage to engage citizens in government practices and innovate in African countries. Afful-Dadzie and Afful-Dadzie's study [16] analyzed the infrastructure of seven open government web portals in Africa and compared their data quality through the perspectives of five media 
practitioners. The study found that data quality features of web portals are not consistent with users' preferences.

These studies point out that African governments are in a state of lost trust; open government could be one of the major actions needed to restore the trust and dignity of public service in African governments [11]. Similarly, Chiviru [5] asserted that the failure to eradicate poverty in Africa is a result of a failure to deal with corruption, inequality, lack of accountability and bad governance. Although the African continent boasts abundant natural resources, the number of people living in extreme poverty is over 100 million. Chiviru [5] sees that, because open government strengthens the checks and balances within government and enables the identification of corrupt individuals, opening information to citizens enables the building of accountability and makes civil servants responsible for integrity in providing services to citizens. Razzano [19] conducted a study with OGP member countries and addressed that, from South African interviews, working together with government departments and agencies was difficult because South Africa did not have a strong coordination framework in holding the same objectives and progressing the implementation of OGP commitments. In Africa, where OGP member countries have made more activities and programs than non-OGP countries, they tend to identify more challenges than counterparts. It is also a concern that, while open government-related activities and programs have been centered on OGP member countries in Africa, non-OGP countries may be alienated from main open government activities.

In light of the above situation of African governments in response to the global open government movement, it is meaningful to conduct Africa-focused research to take a closer look at the African regional context. As the open government movement has been driven by developed countries to date, studies on African countries' open government have been rare. Thus, this study aims to examine how African countries have made effort towards improving their open government levels and to analyze the relationships between the factors of open government. Research questions are formulated as: (1) What levels of open government are African countries positioned in?; (2) What areas need to improve in African countries?; and (3) How do the OGP member countries perform open government in comparison to non-OGP member countries? This assessment of open government in African countries will be useful to analyze the current state of African countries and to examine the areas in which they should improve. The findings of this study will present insights for countries that have similar conditions as African countries to help make policy plans and strategies.

The remainder of this study is organized as follows: Section 2 presents the conceptual framework and objectives of the study. Section 3 explains the data, methods and procedures of conducting the analyses. Section 4 provides the results of the analyses. Section 5 discusses the key points of the results and policy implication. Section 6 concludes with further studies.

\section{Conceptual Framework and Objectives}

With regard to research on open government, there are several global index studies that provide the world's progress scores in open government, such as the Global Open Data Index [20], International Open Data Charter [21], Open Data Readiness Assessment [22], Open Government Index [23], Open Government Standards [24], and Global Government Openness Index $[25,26]$. These indices provide various aspects of government openness with different factors for the world [26]. For example, the Open Government Standards [24], developed by Access Info Europe, assess open government with a focus on the right of access to information and consist of three core areas (e.g., accountability, transparency, and participation). The Global Open Data Index [20] aims to evaluate the state of government data release regarding 15 categories in the administration of government, such as government budget, national statistics, procurement, national laws, administrative boundaries, etc. The Open Data Readiness Assessment [22] provides a methodological toolkit for a government agency to use and plan open government programs with eight dimensions (e.g., 
senior leadership, policy/legal framework, institutional structures, responsibilities and capabilities within government, government data management policies and procedures, demand for open data, civic engagement and capabilities for open data, funding for an open data program, and national technology and skills infrastructure). The Open Government Index [23] measures open government with legal aspects in four dimensions (e.g., publicized laws and government data, right to information, civic participation, and complaint mechanisms). The Open Government Partnership [27] assessed the state of member countries' commitments and action plans when joining the OGP through four dimensions (e.g., accountability, transparency, citizen participation, and technology and innovation).

Accountability indicates the juridical dimensions of governments, governance-related laws or policies in administration. Although some African countries have implemented FOIA or Access to Information Acts, those have been still insufficient; thus, Africa is still confronted with a lack of accountability and bad governance. Transparency indicates transparent government operations and assesses the degree of corruption in governments. Considering that Africa is broadly faced with corruption practices, without the implementation of FOIA - or experiencing unsatisfactory progress even with it-this factor is closely related to the factor of accountability. Citizen participation and freedom indicates the broad engagement and participation of citizens in government operations and social areas. It is based on the perspective that participation by citizens in government should be encouraged in order to build open government. Information and communication technology measures the degree to which ICT facilities and equipment are in place.

Among the existing indices with various viewpoints and focuses, Park and Oh's study examined the different factors and their relationships used in the existing indices and identified that the four factors of the OGP, including "the common aspects of the existing indices and contain broader coverages of open government related aspects comprehensively and impartially" [26] (p. 21). The UN ECA [9] also remarked that open government is based on the philosophy that democracy is a participatory process in which citizens have access to legal rights and play a part in the process, which builds the transparency and accountability of government. Thus, to facilitate the process, the broader and balanced aspects of open government are important. Thus, the Global Government Openness Index adopted the four factors to measure the degree of open government with 134 countries [26]. This study also adopts the four factors of the Global Government Openness Index as a conceptual framework for estimating African countries' Government Openness Index (AGOI), including: (1) accountability (ACC hereafter), (2) transparency (TRA hereafter), (3) citizen participation and freedom (CPF hereafter), and (4) information and communication technology (ICT hereafter).

Although the existing index studies include Africa, they do not focus on African countries, which are currently needed to diagnose the situation related to government openness in African countries and help overcome problems. To fill the gap in existing index studies, the objectives of this study are to:

(1) Estimate African countries' Government Openness Index (AGOI) to see the updated progresses of their open government;

(2) Examine what areas African countries should improve further for sustainable development, and;

(3) Compare the performances of OGP member countries to those of non-OGP countries to see if OGP membership helps improve their progress in open government.

\section{Data and Methods}

\subsection{Data}

According to the coverage of the four factors of the conceptual framework, data sources are adopted from the same existing datasets in developing a Global Government Openness Index (GGOI) [26]. As seen in Table 1, the twelve datasets are taken from internationally authoritative institutions, the most frequently used in relevant fields and 
reliable data sources (e.g., United Nations, World Bank, Economist Intelligence Unit, Freedom House, and Transparency International) to ensure data quality.

Table 1. Factors and data sources of the study.

\begin{tabular}{cll}
\hline Factor & \multicolumn{1}{c}{ Component } & \multicolumn{1}{c}{ Data Source } \\
\hline \multirow{2}{*}{ Accountability (ACC) } & Rule of law & WB, WGI \\
\cline { 2 - 3 } & Government effectiveness & WB, WGI \\
\cline { 2 - 3 } Transparency (TRA) & Regulatory quality & WB, WGI \\
\cline { 2 - 3 } $\begin{array}{c}\text { Citizen Participation and } \\
\text { Freedom (CPF) }\end{array}$ & Control of corruption & WB, WGI \\
\cline { 2 - 3 } & EIU Political participation index & UN EGOV \\
\cline { 2 - 3 } & Freedom of press & Economist Intelligence Unit \\
\hline \multirow{3}{*}{$\begin{array}{c}\text { Information and Communternational } \\
\text { Technology (ICT) }\end{array}$} & Internet users (per 100 people) & WB, WDI \\
\cline { 2 - 3 } & Mobile cellular subscriptions (per 100 people) & WB, WDI \\
\cline { 2 - 3 } & Fixed broadband Internet subscribers (per 100 people) & WB, WDI \\
\cline { 2 - 3 } & Online Service Index & UN EGOV \\
\hline
\end{tabular}

Note: $\mathrm{WB}=$ World Bank, WGI = Worldwide Governance Indicators, WDI = World Development Indicators, UN EGOV = United Nations E-Government Survey.

Regarding the four factors, accountability (ACC) is considered a fundamental factor and composed of the rule of law, government effectiveness and regulatory quality, which are adopted from the Worldwide Governance Indicators (WGI) of the World Bank [28]. Transparency (TRA) is composed of the Corruption Perception Index [29] and control of corruption of the WGI [28] and is taken from Transparency International, which is an international institution committed to corruption and transparency issues.

Citizen participation and freedom (CPF) is composed of the E-Participation Index of the E-Government Survey [30], the political participation values from the Democracy Index [31] and the Freedom of the Press [32]. The E-Participation Index [30] provides online service tools in government services for citizens. The three datasets are reliable, popular for citizens' participation, political systems and freedom. The three data production institutions are internationally well-known and reliable.

Information and communication technology (ICT) is used broadly by the number of internet users per 100 people, mobile cellular subscriptions per 100 people, and fixed broadband Internet subscribers per 100 people, respectively. The numbers are taken from the World Development Indicators (WDI) of the World Bank [33]. The WDI is a specialized data source on global ICT development and facilities. African citizens still have poor infrastructure and fall short of their capacity to use information technologies, which makes it difficult for citizens to involve government administration. As online services have significantly increased for government operations and citizen services, the Online Service Index (OSI) is also taken from the United Nations' E-Government Survey [30], which is an authoritative global data source.

In order to take the most recent data sources, this study adopted datasets from 2006-2019, calculated them quantitatively, and conducted regression analyses. The EParticipation Index and the Online Service Index (OSI) [30] are conducted every two years, so missing years are taken with the interpolation method.

\subsection{Procedures}

This study has been processed as follows. First, to calculate the values of the four factors and AGOI, the scores of 12 adopted datasets should be standardized. Since the datasets have different scales and ranges, the scores have been normalized on a $0-1$ scale and have 
been equalized in the same weights and scales within each factor based on a linear scaling method (LSM) [26,34]. The LSM is also used in developing the E-Government Development Index of the E-Government Survey [30]. The African country list (54 countries) is selected from the World Bank's Country and Lending Groups by country classification (48 countries from sub-Saharan Africa and 6 countries from the Middle East and North Africa) [35]. From the 12 datasets that are taken, due to missing values for a panel data period (2006-2019), the values of 22 countries are not available and removed. Thus, 32 countries are selected with a sample period of 2006 to 2019.

Second, this study checks the dimensionality of the four factors (e.g., ACC, TRA, $\mathrm{CPF}$, and ICT) in building AGOI by applying a principal component analysis (PCA). PCA is a good way to look at variables' variation, project each variable to the first principal component and check their dimensionality. The assumption of the PCA is that if the four factors exist in one dimension, the test validates that the four factors are closely related. Kaiser's rule, which is commonly used, is adopted to decide the number of principal components [36].

Third, to investigate how certain aspects are related to the formation of AGOI, other than the four factors, this study performs a panel regression with the three groups: ALL (32 countries), the Open Government Partnership (OGP) member countries (that are listed in Table 3), and non-OGP countries for the period of 2006-2019. The dependent variable is AGOI and two independent variables are income and the human capital index. To perform a regression, two hypotheses are formulated: (1) the values of income increase AGOI and (2) the values of human capital index increase AGOI. The income level of a country provides a measure of economic development and living standards across countries. The human capital index measures the extent of human development by measuring the years of education attained by citizens in different countries. It consists of four components: "the adult literacy rate; the combined primary, secondary and tertiary gross enrolment ratio; expected years of schooling; and average years of schooling" [30] (p. 235).

Real GDP per capita (constant 2010 USD) is used as an income variable. The real income data are taken from the World Development Indicators of the World Bank [33] and the human capital index data are taken from the United Nations [37]. Like other variables in this study, both the real income (PGDP) and human capital index (HCI) are normalized, as in the studies of Osberg and Sharpe [34] and Park and Oh [26].

For a panel regression, a mathematical formulation can be expressed as follows.

$$
\text { AGOIit }=C+\beta 1 \text { PGDPit }+\beta 2 \text { HClit }+\eta \text { it }
$$

where AGOI is the African government openness index, $\mathrm{C}$ is a constant term, PGDP is the real GDP per capita, $\mathrm{HCI}$ is the human capital index, $\mathrm{i}=1,2 \ldots, \mathrm{N}$ denotes cross-section, $t=1,2 \ldots, T$ denotes a time series, and $\eta$ is an error term. Equation (1) shows AGOI is a dependent variable and PGDP and HCI are independent variables. In a panel analysis, an error component model is commonly used and can consist of fixed effect and random effect models, depending on whether each error term is a fixed or a random variable. Both the fixed effect and random effect models were separately estimated. The Hausman test is performed to choose the fixed effect or random effect model. The null hypothesis of the Hausman test is that the random effect is the correct model, and the null hypothesis is rejected if the test statistic is greater than the critical value, say, the $p$-value is less than 0.05 .

Lastly, this study tests the effect of joining the OGP on AGOI while controlling for the effects of PGDP and HCI for the ALL group.

$$
\text { AGOIit }=C+\beta 1 \text { PGDPit }+\beta 2 \text { HClit }+\beta 3 \text { OGPyeardummyit }+\eta \text { it }
$$

where the OGPyear dummy variable is inserted with 1 after joining the OGP, otherwise, 0 . This test checks the significance of coefficients of the OGPyear dummy. 


\section{Results}

\subsection{African Countries' Government Openness Index}

First, this study tests the dimensionality of the four factors by applying a principal component analysis. Table 2 shows the result of principal component analysis for the four factors, which are ACC, TRA, CPF, and ICT.

Table 2. The results of a principal component analysis.

\begin{tabular}{ccccc}
\hline \multicolumn{5}{c}{ Eigenvalues } \\
\hline Number & Value & Proportion & Cumulative Value & Cumulative Proportion \\
\hline 1 & 2.782 & 0.696 & 2.782 & 0.696 \\
2 & 0.756 & 0.189 & 3.538 & 0.884 \\
3 & 0.342 & 0.086 & 3.880 & 0.970 \\
4 & 0.120 & 0.030 & 4.000 & 1.000 \\
\hline \multicolumn{7}{c}{ Eigenvectors } \\
Variable & PC 1 & PC 2 & PC 3 & PC 4 \\
ACC & 0.537 & -0.411 & 0.163 & 0.719 \\
TRA & 0.534 & -0.410 & 0.261 & -0.692 \\
ICP & 0.510 & 0.238 & -0.825 & -0.058 \\
\hline
\end{tabular}

According to Kaiser's rule [36], the number of the principal component is taken if the eigenvalue is larger than 1 . The table shows that only the eigenvalue of the first principal component (2.782) is larger than 1. Its proportion (cumulative proportion) is 0.696 (approximately 70\%). Thus, one principal component exists, which implies that the four factors are placed in the same dimension (e.g., the assumption is accepted). This test validates that the four factors are closely related and the adoption of the four factors in this test is feasible.

Continuously, Table 3 shows the mean values of African countries by their AGOI scores in 2019 and lists them by the rank of their AGOI scores.

As displayed in Table 3, Cabo Verde is ranked the highest, with an AGOI of 0.707, followed by Tunisia, Botswana, and Ghana. Looking at ACC values, Botswana is ranked at the top, followed by Cabo Verde, South Africa and Namibia. As for TRA scores, Cabo Verde is placed at the top, followed by Botswana and Ghana. These three countries have higher scores than the rest of the countries. CPF shows South Africa is ranked first with a high score, followed by Tunisia, Ghana, and Cabo Verde. These four countries have very high scores when compared to the rest of the countries. ICT scores show that Tunisia places 1st with a remarkably high score, Morocco in 2nd, and South Africa 3rd. It is worth noting that the top ranked countries tend to score relatively higher in all four factors, while lower countries tend to score lower in all respects. This implies that the scores of the factors in one country in Africa are likely to be connected to each other.

Table 4 illustrates the descriptive statistics of the factors included in this study.

The descriptive statistics include the overall picture of the data, such as mean, median, minimum, maximum, and standard deviation values for AGOI and four factors. The magnitude of AGOI ranges from 0.131 to 0.711 . The mean of AGOI in 32 African countries (0.389) is above the median value (0.367). Among the four factors, ACC has the highest mean value (0.553) as well as the highest standard deviation value (0.179), while ICT has the lowest mean (0.238) and the lowest standard deviation values (0.149). ACC's high standard deviation score shows that a bigger gap exists between African countries than that of ICT. 
Table 3. African countries in AGOI and four factors in 2019.

\begin{tabular}{|c|c|c|c|c|c|c|c|}
\hline Rank & Country & $\begin{array}{l}\text { OGP Member } \\
\text { (Year Joined) }\end{array}$ & AGOI & $\mathrm{ACC}$ & TRA & $\mathrm{CPF}$ & ICT \\
\hline 1 & Cabo Verde & Yes (2015) & 0.707 & 0.824 & 0.766 & 0.716 & 0.523 \\
\hline 2 & Tunisia & Yes (2014) & 0.695 & 0.702 & 0.510 & 0.779 & 0.789 \\
\hline 3 & Botswana & No & 0.679 & 0.897 & 0.757 & 0.572 & 0.490 \\
\hline 4 & Ghana & Yes (2011) & 0.670 & 0.720 & 0.742 & 0.742 & 0.478 \\
\hline 5 & South Africa & Yes (2011) & 0.660 & 0.800 & 0.325 & 0.866 & 0.648 \\
\hline 6 & Namibia & No & 0.650 & 0.788 & 0.643 & 0.676 & 0.491 \\
\hline 7 & Morocco & Yes (2018) & 0.595 & 0.699 & 0.464 & 0.557 & 0.661 \\
\hline 8 & Senegal & Yes (2018) & 0.573 & 0.709 & 0.594 & 0.551 & 0.435 \\
\hline 9 & Rwanda & No & 0.521 & 0.789 & 0.526 & 0.419 & 0.349 \\
\hline 10 & Kenya & Yes (2011) & 0.495 & 0.623 & 0.335 & 0.620 & 0.401 \\
\hline 11 & Egypt & No & 0.481 & 0.567 & 0.359 & 0.380 & 0.616 \\
\hline 12 & Burkina Faso & Yes (2016) & 0.474 & 0.572 & 0.473 & 0.536 & 0.315 \\
\hline 13 & Lesotho & No & 0.457 & 0.553 & 0.425 & 0.543 & 0.304 \\
\hline 14 & Tanzania & No & 0.456 & 0.514 & 0.419 & 0.516 & 0.374 \\
\hline 15 & Algeria & No & 0.437 & 0.462 & 0.367 & 0.345 & 0.575 \\
\hline 16 & Zambia & No & 0.414 & 0.560 & 0.358 & 0.459 & 0.279 \\
\hline 17 & Uganda & No & 0.403 & 0.606 & 0.231 & 0.473 & 0.303 \\
\hline 18 & Ethiopia & No & 0.402 & 0.530 & 0.398 & 0.440 & 0.240 \\
\hline 19 & Malawi & Yes (2013) & 0.395 & 0.552 & 0.315 & 0.514 & 0.197 \\
\hline 20 & Togo & No & 0.389 & 0.504 & 0.308 & 0.454 & 0.289 \\
\hline 21 & Nigeria & Yes (2016) & 0.371 & 0.429 & 0.230 & 0.439 & 0.385 \\
\hline 22 & Mozambique & No & 0.367 & 0.459 & 0.281 & 0.503 & 0.225 \\
\hline 23 & Liberia & Yes (2011) & 0.357 & 0.372 & 0.355 & 0.519 & 0.181 \\
\hline 24 & Mauritania & No & 0.355 & 0.546 & 0.283 & 0.355 & 0.238 \\
\hline 25 & Niger & No & 0.349 & 0.525 & 0.360 & 0.381 & 0.130 \\
\hline 26 & Guinea & No & 0.340 & 0.437 & 0.263 & 0.402 & 0.257 \\
\hline 27 & Angola & No & 0.334 & 0.403 & 0.237 & 0.461 & 0.234 \\
\hline 28 & Cameroon & No & 0.322 & 0.439 & 0.205 & 0.325 & 0.320 \\
\hline 29 & Zimbabwe & No & 0.316 & 0.312 & 0.193 & 0.414 & 0.345 \\
\hline 30 & Sudan & No & 0.272 & 0.256 & 0.259 & 0.317 & 0.257 \\
\hline 31 & Congo, Rep. & No & 0.241 & 0.320 & 0.133 & 0.296 & 0.215 \\
\hline 32 & Libya & No & 0.178 & 0.069 & 0.156 & 0.175 & 0.310 \\
\hline
\end{tabular}

Table 4. Descriptive statistics of AGOI and four factors.

\begin{tabular}{lccccc}
\hline Statistics & AGOI & ACC & TRA & CPF & ICT \\
\hline Mean & 0.389 & 0.553 & 0.368 & 0.399 & 0.238 \\
Median & 0.367 & 0.554 & 0.345 & 0.385 & 0.206 \\
Minimum & 0.131 & 0.069 & 0.065 & 0.082 & 0.013 \\
Maximum & 0.711 & 0.949 & 0.820 & 0.884 & 0.789 \\
Std. Dev. & 0.137 & 0.179 & 0.171 & 0.158 & 0.149 \\
\hline Observations & 448 & 448 & 448 & 448 & 448 \\
\hline
\end{tabular}

To examine the overall trends of AGOI with African countries, Figure 1 displays the trend of AGOI and four factors with their values in 2006 and 2019, differences and CAGR (cumulative annual growth rate) for the period of 2006-2019. The differences in the values are taken by subtracting the value of 2006 from that of 2019.

Figure 1 and Table 5 shows that AGOI has continuously increased 0.328 in 2006 to 0.449 in 2019 with a CAGR of $2.45 \%$, which is a positive sign. Considering the trends of the four factors for the period, ICT has increased the most from 0.097 in 2006 to 0.371 in 2019 , resulting in a difference between the two years of 0.274 . The CAGR of ICT during the period is $10.89 \%$, which is the biggest amount among the four factors, as well as AGOI. The second highest increase among the four factors is CPF, which has increased from 0.312 in 2006 to 0.492 in 2019, resulting in a difference of 0.180 and a CAGR of $3.56 \%$. TRA has 
also increased from 0.349 in 2006 to 0.383 in 2019 with a CAGR of $0.74 \%$. ACC, however, has slightly decreased during the period, resulting in a negative difference of -0.005 . Even though its decrease is a tiny amount, it is noticeable to see that only ACC has been reduced among the four factors. To keep AGOI constantly increasing, it seems that ICT and CPF have mainly contributed to an increase in AGOI during the period.

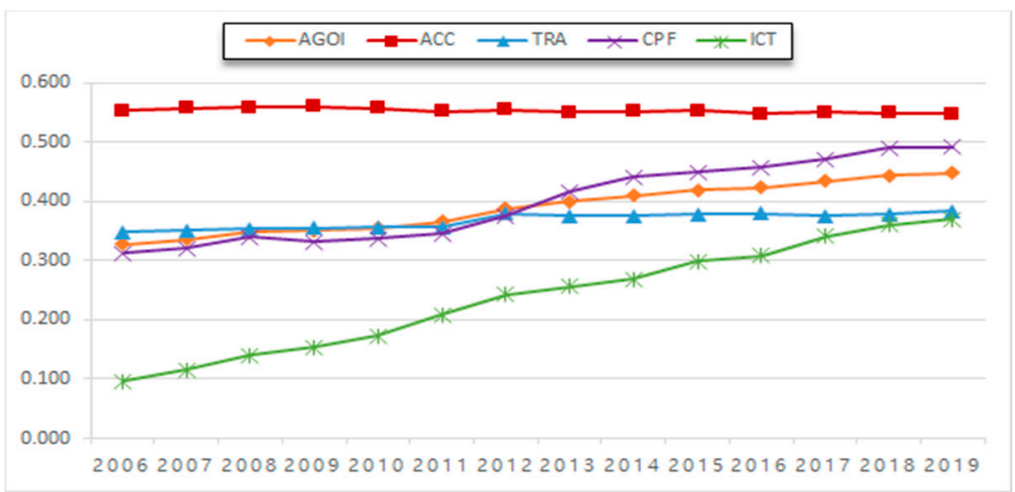

Figure 1. Performance of AGOI and four factors.

Table 5. Annual value, difference and CAGR of AGOI and four factors.

\begin{tabular}{cccccc}
\hline Value & AGOI & ACC & TRA & CPF & ICT \\
\hline 2006 & 0.328 & 0.553 & 0.349 & 0.312 & 0.097 \\
2019 & 0.449 & 0.548 & 0.383 & 0.492 & 0.371 \\
The entire period & 0.389 & 0.553 & 0.367 & 0.399 & 0.238 \\
Difference (2019-2006) & 0.121 & -0.005 & 0.035 & 0.180 & 0.274 \\
CAGR (\%, 2006-2019) & 2.45 & -0.07 & 0.74 & 3.56 & 10.89 \\
\hline
\end{tabular}

Note: CAGR = cumulative annual growth rate.

Over the time period, the ACC line of African countries remains almost the same or is a slightly lower line, while the TRA line slightly increases from 2006 to 2012 and then lowers. Surprisingly, ICT has rapidly and dramatically increased during the period. $\mathrm{CPF}$ also shows constant increases over the period, making a parallel line with ICT. AGOI performs well with a constant increase over the period, looking like a middle line in the four factor lines.

\subsection{Correlation}

Table 6 shows correlative relations of AGOI with four factors for the full period by using panel data of all countries.

Table 6. Correlations of AGOI and four factors.

\begin{tabular}{cccccc}
\hline Factor & AGOI & ACC & TRA & CPF & ICT \\
\hline AGOI & 1.000 & 0.892 & 0.886 & 0.847 & 0.696 \\
ACC & 0.892 & 1.000 & 0.879 & 0.637 & 0.398 \\
TRA & 0.886 & 0.879 & 1.000 & 0.615 & 0.405 \\
CPF & 0.847 & 0.637 & 0.615 & 1.000 & 0.585 \\
ICT & 0.696 & 0.398 & 0.405 & 0.585 & 1.000 \\
\hline
\end{tabular}

As for AGOI, the correlations with ACC, TRA and CPF tend to be high with the highest ACC score (0.892). These three factors have a positive impact on the levels of AGOI. In the case of ACC, a correlation with TRA is high, followed by CPF and ICT. In the meantime, the correlations of ICT tend to have lower scores and a correlation of ICT and AGOI is the highest (0.696). 


\subsection{Comparisons of OGP and NOGP}

To examine the differences of OPG and non-OGP countries in building AGOI scores and to see which factor affects their difference, this section makes a comparative analysis of the two groups. Table 3 lists the countries of OGP members (OGP hereafter) and their non-OGP counterparts (NOGP hereafter) as of April 2020 from the OGP site (2021). From the 32 African countries selected for the study, while the number of OGP member countries is 11 , that of non-OGP countries is 21 .

To see the comparative performances of OGP and non-OGP countries in constructing AGOI, Table 7 displays the mean values of the two country groups by the values of AGOI and four factors at the beginning year of 2006 and in the final year, 2019. The differences in each column are taken by subtracting the value of 2006 from that of 2019.

Table 7. Comparisons of AGOI and four factors by OGP and non-OGP.

\begin{tabular}{llccccc}
\hline Group & \multicolumn{1}{c}{ Year } & AGOI & ACC & TRA & CPF & ICT \\
\hline \multirow{3}{*}{ OGP } & 2006 & 0.395 & 0.650 & 0.409 & 0.392 & 0.128 \\
& 2019 & 0.545 & 0.636 & 0.464 & 0.622 & 0.456 \\
& Diff (2019-2006) & 0.150 & -0.014 & 0.055 & 0.230 & 0.328 \\
\hline \multirow{3}{*}{ NOGP } & 2006 & 0.292 & 0.502 & 0.317 & 0.270 & 0.080 \\
& 2019 & 0.398 & 0.501 & 0.341 & 0.424 & 0.326 \\
& Diff (2019-2006) & 0.106 & -0.001 & 0.024 & 0.154 & 0.246 \\
Difference & 2006 & 0.103 & 0.148 & 0.093 & 0.122 & 0.048 \\
NOGP) & Diff (2019-2006) & 0.146 & 0.135 & 0.123 & 0.198 & 0.130 \\
\hline
\end{tabular}

For the OGP group, AGOI has increased from 0.395 in 2006 to 0.545 in 2019, resulting in a positive change of 0.150 . Among the four factors, ICT has performed the most with a difference of 0.328 over the period. CPF places in second with a difference of 0.230 and TRA is third with 0.055 . The value of ACC for the OGP group has been reduced from 0.650 in 2006 to 0.636 in 2019, resulting in a difference of -0.014 .

For the non-OGP group, AGOI has also increased from 0.292 in 2006 to 0.398 in 2019, resulting in a positive change of 0.106 . In terms of the magnitude of change, the order is ICT, CPF, TRA and ACC. Among the four factors, ACC of the OGP group is negative, and that of the non-OGP group also shows a negative change from 2006 to 2019.

Looking at the differences in the OGP group from the non-OGP group by subtracting the value of 2006 from that of 2019, the OGP group's differences in AGOI, ICT, CPF, and TRA are larger than those in the non-OGP group. The difference of ACC between OGP and non-OGP has decreased from 0.148 in 2006 to 0.135 in 2019. It is conspicuous that both the OGP and non-OGP countries show the same pattern of increases in AGOI, ICT, CPF and TRA by order, as well as a decrease in ACC. Most of all, OGP member countries have performed better than the non-OGP counterparts in terms of AGOI, ICT, CPF and TRA except for ACC. These observations imply that participating in the OGP seems helpful in enhancing their government openness and the differences between the two groups (0.043) is meaningful to OGP countries.

To visually present the means of AGOI and four factors by OGP members and non-OGP countries, Figure 2 demonstrates the clear differences between the two groups in graphs.

In all five graphs, the lines of OGP are placed in higher positions than those of their non-OGP counterparts, which boosts OGP countries. The two lines of AGOI moved upwards in parallel until 2012, when the gap between the lines became larger. Since 2017, they have been going in parallel again. The year was after the OGP began in 2011, and since then, more member countries have joined the OGP. The lines of ACC have been steadily in parallel from 2006 to 2016, and after a small decrease in 2015, they returned into parallel. The lines of TRA show that a difference in the two lines has increased and decreased by 
2011. Then, the gap between the two TRA lines increased from 2014 to 2019. Overall, the cases of ACC and TRA are likely to ensure that the gap between the two lines remains relatively steady.
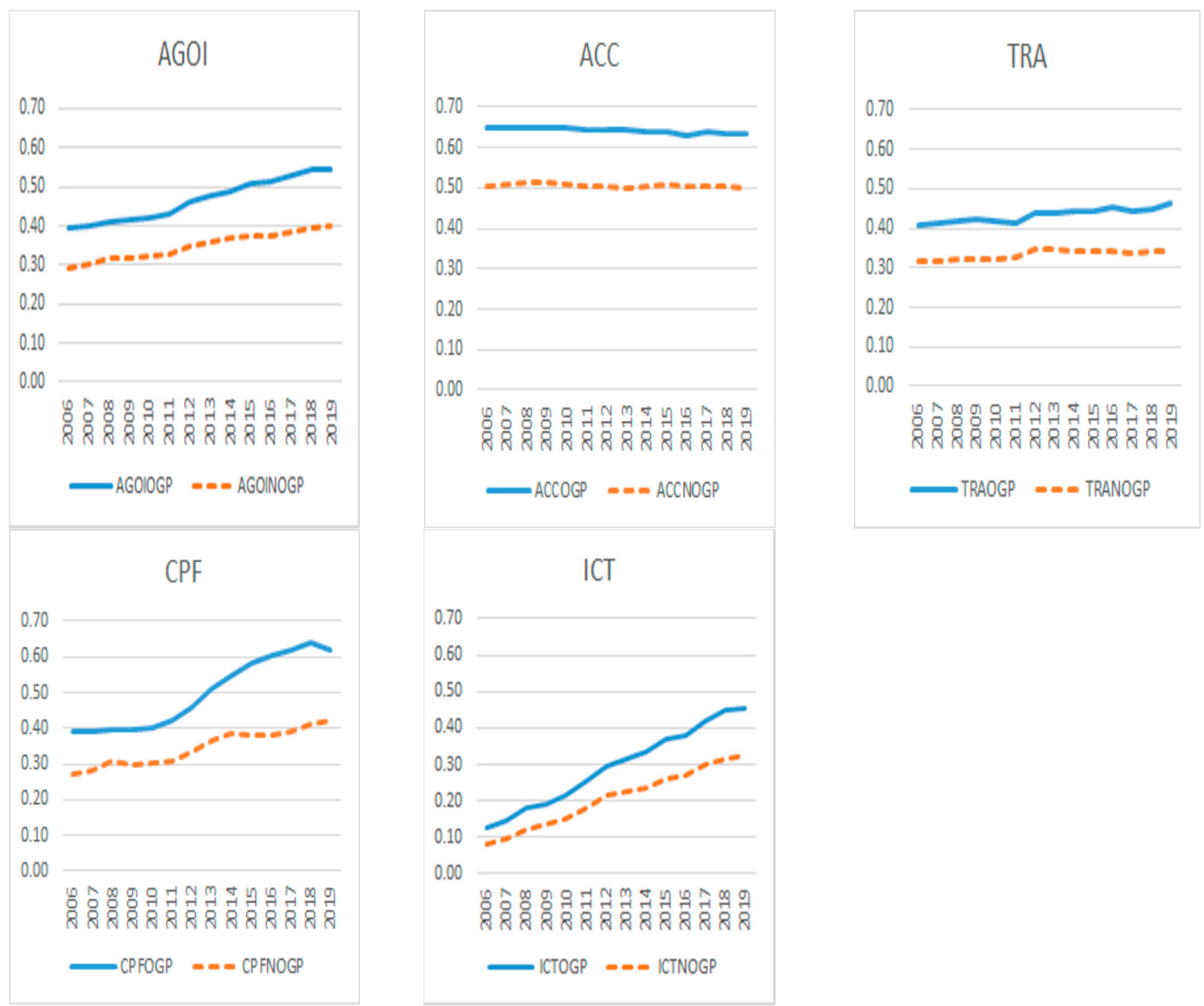

Figure 2. Means of AGOI and four factors by OGP and non-OGP groups.

In the case of CPF, with a decrease from 2006 to 2008, the gap in the two CPF lines was significantly high from 2014 to 2018, with a decrease in 2019. This agrees with the gap of AGOI lines, which also became larger in 2014. The case of ICT is prominent in order to see that the gap between the two groups constantly and steadily increased from 2006 to 2019 .

Looking at the comparative performances of the two groups in the past year, 2019, as the AGOI scores of OGP are much higher than those of the non-OGP group, the values of non-OGP could only reach approximately 73\% in AGOI, 79\% in ACC, 73\% in TRA, 68\% in $\mathrm{CPF}$, and $71 \%$ in ICT, respectively. Among the five cases, while the differences of ACC, TRA and ICT are similar amounts, the difference of CPF is noticeably the highest. This implies that the CPF score of the OGP group tends to be much higher than those of the OGP countries, which reflects the fact that OGP countries perform especially well in the CPF score. 


\subsection{Panel Regressions}

For the first regression analysis with AGOI as a dependent variable, three models are used for both the fixed effect model and the random effect model, depending on the independent variables. The first model has a constant term and GDP per capita (PGDP) as independent variables. The second model has a constant term and human capital index (HCI) as independent variables. The third model has three independent variables such as constant term, PGDP, and HCI. In order to select a model between the fixed effect model and random effect model, the Hausman test is performed and applied to Model 1 vs. Model 4, Model 2 vs. Model 5, and Model 3 vs. Model 6.

Table 8 demonstrates the results of the panel regression and the Hausman test for three groups: ALL (32 African countries), OGP (11 countries) and Non-OGP (21 countries).

Table 8. The effects of PGDP and HCI on AGOI for ALL, OGP and NOGP groups.

\begin{tabular}{|c|c|c|c|c|c|c|c|}
\hline \multirow{2}{*}{ Group } & & \multicolumn{3}{|c|}{ Fixed Effect } & \multicolumn{3}{|c|}{ Random Effect } \\
\hline & & Model 1 & Model 2 & Model 3 & Model 4 & Model 5 & Model 6 \\
\hline \multirow{9}{*}{ ALL } & $\mathrm{C}$ & 0.342 & 0.345 & 0.295 & 0.322 & 0.569 & 0.502 \\
\hline & & $(0.000)$ & $(0.000)$ & $(0.000)$ & $(0.000)$ & $(0.000)$ & $(0.000)$ \\
\hline & PGDP & 0.293 & & 0.295 & 0.416 & & 0.387 \\
\hline & & $(0.000)$ & & $(0.000)$ & $(0.000)$ & & $(0.000)$ \\
\hline & $\mathrm{HCI}$ & & 0.084 & 0.089 & & -0.343 & -0.333 \\
\hline & & & $(0.019)$ & $(0.007)$ & & $(0.000)$ & $(0.000)$ \\
\hline & Hausman test & & & & 1.505 & 21.761 & 7.869 \\
\hline & & & & & $(0.220)$ & $(0.000)$ & $(0.020)$ \\
\hline & Adjusted $\mathrm{R}^{2}$ & 0.954 & 0.948 & 0.955 & 0.111 & 0.262 & 0.359 \\
\hline \multirow{9}{*}{ OGP } & $\mathrm{C}$ & 0.199 & 0.381 & 0.124 & 0.199 & 0.636 & 0.360 \\
\hline & & $(0.000)$ & $(0.000)$ & $(0.011)$ & $(0.000)$ & $(0.000)$ & $(0.000)$ \\
\hline & PGDP & 1.648 & & 1.609 & 1.647 & & 1.602 \\
\hline & & $(0.000)$ & & $(0.000)$ & $(0.000)$ & & $(0.000)$ \\
\hline & $\mathrm{HCI}$ & & 0.167 & 0.155 & & -0.321 & -0.293 \\
\hline & & & $(0.001)$ & $(0.001)$ & & $(0.000)$ & $(0.000)$ \\
\hline & Hausman test & & & & 125.539 & 19.002 & 78.142 \\
\hline & & & & & $(0.000)$ & $(0.000)$ & $(0.000)$ \\
\hline & Adjusted $\mathrm{R}^{2}$ & 0.957 & 0.262 & 0.960 & 0.356 & 0.150 & 0.492 \\
\hline \multirow{9}{*}{ NOGP } & $\mathrm{C}$ & 0.307 & 0.369 & 0.319 & 0.302 & 0.524 & 0.478 \\
\hline & & $(0.000)$ & $(0.000)$ & $(0.000)$ & $(0.000)$ & $(0.000)$ & $(0.000)$ \\
\hline & PGDP & 0.255 & & 0.253 & 0.289 & & 0.272 \\
\hline & & $(0.000)$ & & $(0.000)$ & $(0.000)$ & & $(0.000)$ \\
\hline & $\mathrm{HCI}$ & & -0.040 & -0.023 & & -0.335 & -0.330 \\
\hline & & & $(0.330)$ & $(0.603)$ & & $(0.000)$ & $(0.000)$ \\
\hline & Hausman test & & & & 0.918 & 11.721 & 5.170 \\
\hline & & & & & $(0.338)$ & $(0.001)$ & $(0.075)$ \\
\hline & Adjusted $\mathrm{R}^{2}$ & 0.948 & 0.938 & 0.948 & 0.093 & 0.334 & 0.421 \\
\hline
\end{tabular}

Note: Value in parenthesis () is $p$-value. $p$-value $<0.01(0.05,0.1)$ significant at $1 \%(5 \%, 10 \%)$. ALL $=32$ African countries, OGP $=$ OGP member countries, NOGP $=$ non-OGP countries. 
The table provides adjusted $\mathrm{R}^{2}$ as overall model fitness. For the ALL group with 32 African countries, based on the Hausman test, Models 2, 3 and 4 are chosen. Both Model 3 and Model 4 show that the income variable has a positive and statistically significant effect on AGOI. Both Model 2 and Model 3 also show that the HCI variable has a positive and statistically significant effect on AGOI. Thus, the two hypotheses for the ALL group are accepted at the 5\% significance level. Comparing the magnitude of income and HCI variables in Model 3, the income effect (0.295) dominates the HCI effect (0.089).

For the OGP group in Africa, Models 1, 2, and 3 are selected. The panel regression results show that both income and HCI have positive and statistically significant effects on AGOI, as observed in the ALL case. Again, the relative effect of income is much larger than that of HCI. Thus, the two hypotheses for the OGP group are accepted at the 5\% significance level. For non-OGP countries in Africa, Models 2, 4 and 6 are selected, based on the Hausman test. Like ALL and OGP groups, the income variable is positively significant, as shown in the selected models. HCI, however, is either insignificant (Model 2) or has a negatively significant effect (Model 6). Thus, for the non-OGP group, the first hypothesis is accepted and the second hypothesis is rejected at the $5 \%$ significance level.

Comparing the three groups together-ALL, OGP, and non-OGP-income has a positively and statistically significant effect at the $1 \%$ significance level, which is robust. Income effect in OGP has a more dominant effect than that of non-OGP. In the case of HCI, only ALL and OGP groups have a positively and statistically significant effect, which is robust. That of the non-OGP group is either insignificant or has a negatively significant effect. Considering the HCI effects between ALL and OGP, the HCI effect of OGP dominates that of non-OGP.

As the second regression analysis, this study tests the existence and relative strength of the effect of joining the OGP on AGOI while controlling for the effects of PGDP and HCI. The panel regression results are shown in Table 9.

Table 9. The effects of joining OGP on AGOI in the ALL group.

\begin{tabular}{lcc}
\hline \multicolumn{1}{c}{ Independent Variable } & Fixed Effect & Random Effect \\
\hline C & 0.301 & 0.470 \\
\hline PGDP & $(0.000)$ & $(0.000)$ \\
\hline & 0.288 & 0.348 \\
\hline HCI & $(0.000)$ & $(0.000)$ \\
\hline & 0.074 & -0.278 \\
\hline OGPyeardummy & $(0.025)$ & $(0.000)$ \\
\hline & 0.017 & 0.061 \\
\hline Hausman test & $(0.005)$ & $(0.000)$ \\
\hline & & 9.630 \\
\hline Adjusted ${ }^{2}$ & & $(0.022)$ \\
\hline
\end{tabular}

To see the overall results, Figure 3 illustrates the main findings of this study in a visual form. 


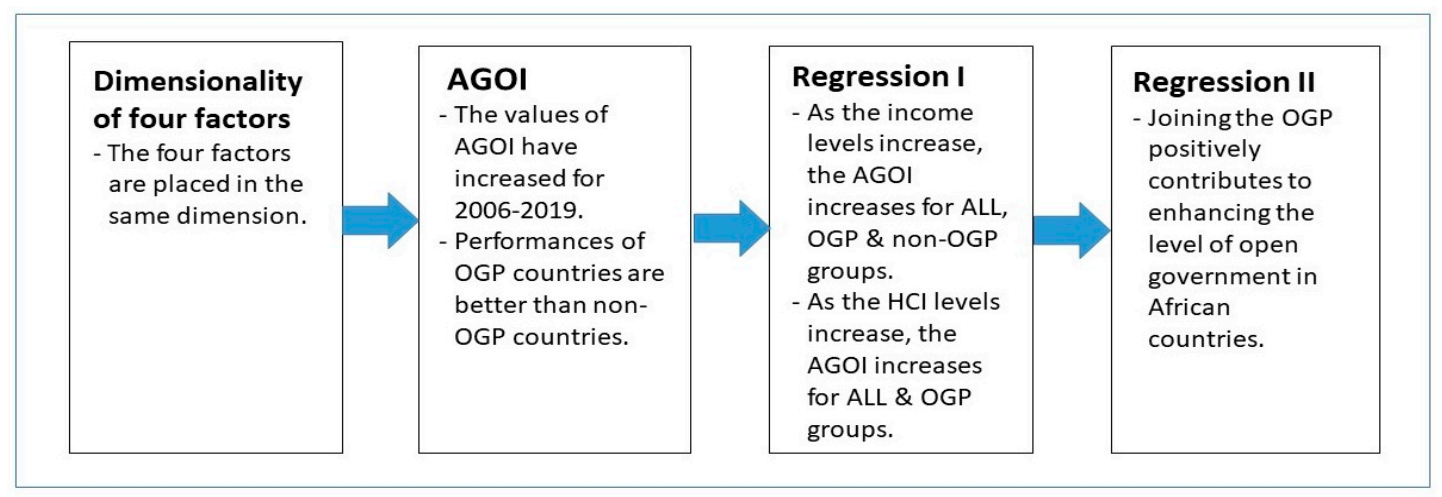

Figure 3. The key points of the study.

\section{Discussion}

\subsection{Performance of AGOI and Four Factors}

This study aims to examine African countries' progress toward open government and to investigate the factors that the African countries should improve to achieve sustainable development. In addition, this study compares the performances of African OGP members and non-OGP countries in progressing open government. The African countries' Government Openness Index (AGOI) has been developed in 32 countries with four factors (ACC (accountability), TRA (transparency), CPF (citizen participation and freedom) and ICT (information and communication technology)) during the period of 2006-2019. To validate the dimensionality of the four factors, three factors (ACC, TRA, and CPF) can be seen in the same dimension by the nature of the concepts, as these three factors are related to governance. Technological capabilities boost all levels of accountability, transparency and citizen participation; therefore, a technological factor plays the role of a channel by cooperating with the three factors directly and indirectly in all stages of the processes. The principal component analysis demonstrates that all four factors are placed in one dimension, proving they are closely inter-related. This result confirms that the four factors interact and complement each other in a cyclic way $[9,26]$. Thus, adopting the four factors in developing AGOI is feasible.

Looking at the movement of AGOI as seen in Figure 1, African countries have continuously increased from 2006 to 2019, with a cumulative annual growth rate (CAGR) of $2.45 \%$. Comparing AGOI with the global government openness index (GGOI) that was developed by Park and Oh [26], AGOI's annual growth rate is faster during the period of 2006-2019 than that of GGOI (2.09\%) for 2006-2015. This is a positive observation for Africa. Among the four factors, while the TRA line has increased slightly at $0.74 \%$, the values of CPF (3.56\%) and ICT (10.89\%) have increased at higher growth rates. CPF scores in Africa have increased steadily with slight fluctuations, which is encouraging for African countries with regard to improving the degree of open government. ICT has also improved significantly, with the biggest difference of 0.274 . In comparison to the GGOI [26], the annual growth rate of ICT (10.89\%) in Africa is much higher than that of GGOI (6.32\%) for 2006-2015. The levels of technology and infrastructure in Africa are so low in the first year that Africa's increasing pace of ICT could outperform that of the world because some progress in technology and infrastructure can be seen as self-evident in the context of the modernization paradigm. CPF and ICT are the two main contributors to the constant increases in AGOI for the period, which agrees with the study of Park and Oh [26]. CPF and ICT scores were low in the beginning of the year 2006; since then, they have increased somewhat, but are still lower than the levels of ACC and TRA.

As for the ACC score of Africa, it is worth pointing out that the scores of ACC in African countries have remained unchanged, or even slightly reduced by a small amount, which is the same tendency of the Government Openness Index with developing countries and GGOI $[25,26]$ and Open Government Standards [24]. This is understandable because it 
is difficult and time-consuming to enact legislation, renew a legal system, and establish accountability through laws. The fact that the current level of ACC is not satisfied is also observed in country cases of Sierra Leone [14] and Liberia [15]. For example, in Liberia's study [18], its Freedom of Information Act (FOIA) has been implemented but government transparency and accountability are still poor in corruption practices across government agencies. The scores of ACC and AGOI reflect that Africa is still in a state that lacks accountability and governance, which is agreeable with the findings of existing studies [12,14,15]. Furthermore, the gap of ACC between African countries is bigger (0.179) than those of other factors. Chiviru [5] addressed that there is a relationship between citizen participation and building accountability and integrity. Thus, African countries may not be currently using ACC enough to increase TRA or CPF. Simultaneously, CPF does not seem to function properly with ACC.

Regarding individual countries, the top ranked countries according to their AGOI scores (e.g., Cabo Verde, Botswana, Ghana, Morocco, Namibia, South Africa and Tunisia) tend to be placed in higher positions in other factors than the rest of the countries. The reasons why these countries are placed in higher positions may vary depending on the context within each country, but this tendency is likely valid since the four factors are inter-connected complementarily to each other. If the accountability in a country functions well, it should evolve to promote citizen participation, leading to building transparency in sharing and interactive procedures and, consequently, establishing accountability [5]. Among several possibilities for the leading countries in Africa, one of their commonalities is joining the OGP.

\subsection{Comparisons of OGP and Non-OGP Countries}

In comparison to the scores of OGP and non-OGP groups in making AGOI, what stands out clearly is that OGP member countries perform much better than non-OGP countries. Seven out of the top 10 countries are OGP members. The countries that joined the OGP first from 2011 to 2015 (Cabo Verde, Ghana, Kenya, South Africa, Tunisia) tend to score higher than the rest of the countries do. As seen in Figure 2, the OGP group reached much better scores than their non-OGP counterparts, with positive differences in AGOI, ICT, CPF, and TRA, except ACC. It seems that participating in the OGP positively contributes to improving their government openness. While both the OGP and non-OGP countries have made similar increases in AGOI, ICT, CPF and TRA, the gap of AGOI between the two groups increased in 2011, when OGP member countries started to join. The gap of CPF lines between OGP and non-OGP groups has increased impressively in great amounts since 2014 from the non-OGP line. The gap of ICT between the two groups has also increased constantly and enormously from 2006 to 2019. Thus, by using the high levels of CPF and ICT, OGP member countries should make further effort to supplement the factors that are lacking. Tunisia is a good example to follow. By using its high ICT capacity, the Tunisian government has tried to improve transparency, such as by developing mobile applications, open data portals and cultural agenda systems using an integrated electronic civil petition and corruption reporting platform [38].

To investigate whether other factors affect government openness in African countries, a regression of AGOI was conducted with income (GDP per capita) and human capital index (HCI) variables. The result of the regression shows that the higher the income levels, the higher the AGOI for ALL, OGP and non-OGP groups. The income effect in OGP members is bigger than the non-OGP group. In the case of HCI, only ALL and OGP groups have positively and statistically significant coefficients. In the second regression, the effect of joining the OGP on AGOI while controlling for the effects of PGDP and HCI is also positive. This result shows again that joining the OGP positively contributes to enhancing the level of open government in Africa. Looking at South Africa as a representative OGP member country, South Africa is one of eight OGP founding members and has played an active role in participating in regional initiatives in Africa. Its PGDP is relatively higher than sub-Saharan African countries and in 2019 it belonged to the upper middle-income 
group. South Africa's end-of-term reports detail that South Africa has completed more commitments and achieved a high degree of citizen participation, such as by developing interactive and open data portals on budget and expenditure outcomes, citizen-based monitoring, forming a National Anti-Corruption Task Team, and so forth [39]. The area of improvement that is needed in South Africa would be to support transparency by using the high levels of CPF, ACC and ICT, gradually setting down a government openness framework in South Africa.

\subsection{Policy Implication}

The findings of this study are useful to observe countries' advantages and disadvantages in improving the degree of AGOI and to help make policy plans and strategies in individual countries. For countries that have similar conditions as African countries, it is recommended that boosting both constantly increasing citizen participation and technology infrastructure is a suitable strategy. The ICT gap between African countries is smaller (0.149) than the other three factors. It is relatively easier to install ICT facilities than to rebuild accountability or transparency within a country. By using rapidly increasing ICT facilities, citizen participation should be cultivated to provide more online services for citizens. Governments or civil society organizations should provide open data platforms or portals (e.g., OpenAFRICA or KODI) to the public in order to make open data accessible and usable for citizens. African governments should improve the ICT usage capacity for citizens to know how to use technological facilities. As a reminder, HCI has a positive effect on AGOI formation. It is essential to enhance human capacities toward improving citizen participation and transparency in open government. Governments should provide various ICT education programs at schools and communities for citizens to improve their ICT literacy level. Then, citizens can make their voices louder in order to make government data more acquirable and accessible, and to engage them in the delivery of government operations (e.g., government budget, contracting, decision-making, legislative procedures). Thus, the levels of citizen participation should be expanded to encourage higher levels of transparency and accountability.

Most of all, it is recommended that African countries join the OGP in order to move towards improving government openness. When countries join the OGP, they are asked to develop commitments and to assess their action plans on the progress of their commitments every two years. Through this self-evaluation process, countries will have opportunities to increase awareness, set goals, complete action plans, analyze incomplete plans, disclose information, participate in expert consulting, etc. Joining the OGP means reshaping one country's values under the framework of open government. The OGP promotes reforming government in the implementation processes of action plans, within a new atmosphere of open government. Countries should consider the extent of disparities in facilitating their action plans and take assessment approaches through the lens of the cultural biases of the OGP, as individual countries may have regional, political and cultural differences based on their own situations.

\subsection{Limitations of the Study}

The results of this study are limited to the estimation of the adopted four factors with selected data sources. Due to the availability of data, the sample countries and period were chosen. If other data components are taken, the results may be different. The level of ICT that indicates the ownership of, or access to, infrastructural facilities and tools may not represent the exact access to government information.

\section{Conclusions}

This study attempts to examine the current phases of open government in African countries through four factors and to investigate which factors have contributed to improving their levels by OGP and non-OGP groups. To create the four factors, 12 datasets have been adopted from trustworthy and authoritative institutions that presumably maintain 
the quality and reliability of their data. The period and sample countries were selected with the most up to date data. The AGOI is unique by adopting well-rounded factors and seeing African countries' pictures of the progress of open government according to African conditions. The results of this study show that as the selected four factors are unidimensional, they should all be considered when examining government openness. The result of this study is meaningful in examining the areas that countries should improve for sustainable development. The methods and results of this study would be applicable to any part of the world, especially in developing countries that have similar conditions as African countries.

Further studies could be conducted to estimate government openness levels of other groups of countries (e.g., developing countries, emerging market economies, Asian countries) by income group in order to see how each income group relates to their performance. To understand whether the trends of African countries are increasing or decreasing compared to the rest of world, further studies could compare the gap between Africa and the more developed parts of the world. To investigate the motivations of the top-positioned countries, in-depth country studies could be conducted further with individual countries' unique and complicated contexts.

Funding: This study received no external funding.

Institutional Review Board Statement: Not applicable.

Informed Consent Statement: Not applicable.

Data Availability Statement: Public datasets are available at the data sites. The data presented in this study are available upon reasonable request.

Acknowledgments: The author thanks collaborative researchers for their advice and technical help. The author also thanks the anonymous reviewers for constructive comments.

Conflicts of Interest: The author declares no conflict of interest.

\section{References}

1. Open Government Partnership. Members. 2021. Available online: https://www.opengovpartnership.org/our-members (accessed on 20 April 2021).

2. Sendugwa, G. OGP in Africa: Civil Society Organizations Share Experiences. 2013. Available online: https://www. opengovpartnership.org/stories/ogp-africa-civil-society-organizations-share-experiences (accessed on 20 April 2021).

3. Ranchod, S. OGP Africa: Kicks off. 2013. Available online: http://www.opengovpartnership.org/sites/default/files/working_ groups / Africa\%20OGP\%20Kicks\%20Off.pdf (accessed on 20 April 2021).

4. Banzet, A. \#CAFDO2017: The First Francophone African Conference on Open Data and Open Government. 2017. Available online: https:/ / www.opengovpartnership.org/stories/cafdo2017-first-francophone-african-conference-on-open-data-and-opengovernment (accessed on 20 April 2021).

5. Chiviru, T. Is Open Government a Solution to Ending Poverty in Africa? 2017. Available online: https://www. opengovpartnership.org/stories/open-government-solution-ending-poverty-africa (accessed on 20 April 2021).

6. Africa Open Data Conference. 2017. Available online: http:/ / africaopendata.net (accessed on 20 April 2021).

7. Coder for Africa. OpenAFRICA Africa's Largest Volunteer Driven Open Data Platform. 2021. Available online: https:// africaopendata.org (accessed on 20 April 2021).

8. Centre for Public Impact. Kenya Open Data Initiative. 2016. Available online: https:/ /www.centreforpublicimpact.org (accessed on 20 April 2021).

9. United Nations Economic Commission for Africa. Unlocking the Potentials of Open Government in Africa: Policy, Legal and Technical Requirements for Open Government Implementation in Africa. 2017. Available online: https://www.uneca.org/sites/ default/files/PublicationFiles/unlocking_the_potential_of_open_government-final.pdf (accessed on 20 April 2021).

10. Adu, K.K.; Patrick, N.; Park, E.G.; Adjei, E. Evaluation of the implementation of electronic government in Ghana. Inf. Polity Int. J. Gov. Democr. Inf. Age 2018, 23, 81-94. [CrossRef]

11. Ndaguba, E.; Ijeoma, E. Digital open government in Africa: A strategy for bridging citizens' gap. Electron. Gov. Int. J. 2018, 14, 115-133. [CrossRef]

12. Kuunifaa, C.D. Access to information legislation as a means to achieve transparency in Ghanaian governance: Lessons from the Jamaican experience. IFLA J. 2012, 38, 175-186. [CrossRef]

13. Omotayo, F.O. The Nigeria freedom of information law: Progress, implementation challenges and prospects. Libr. Philos. Pract. 2015, 1, 1-18. 
14. Svärd, P. Freedom of information laws and information access. Inf. Dev. 2017, 33, 190-198. [CrossRef]

15. Svärd, P. Has the Freedom of Information Act enhanced transparency and the free flow of information in Liberia? Inf. Dev. 2018, 34, 20-30. [CrossRef]

16. Afful-Dadzie, E.; Afful-Dadzie, A. Open government data in Africa: A preference elicitation analysis of media practitioners. Gov. Inf. Q. 2017, 34, 244-255. [CrossRef]

17. Seegolam, A.; Sukhoo, A.; Bhoyroo, V. Spurring Innovation through Open Government Data for Africa. In Proceedings of the 2016 IST-Africa Week Conference, Durban, South Africa, 11-13 May 2016; Available online: https://ieeexplore.ieee.org/document/75 30638 (accessed on 20 April 2021).

18. Wamukoya, J.M. The role of record keeping and open government data initiatives in fostering a critical development of open government policies and public services in sub-Saharan Africa. Mousaion 2012, 30, 117-127.

19. Razzano, G. Connecting the Dots: The Coordination Challenge for Open Government Partnerships in South Africa. 2016. Available online: https://www.corruptionwatch.org.za/wp-content/uploads/2016/09/Odac-Book_Digital.pdf (accessed on 20 April 2021).

20. Open Knowledge International. The Global Open Data Index. Available online: https:/ / index.okfn.org/place (accessed on 20 April 2021).

21. Open Data Charter. International Open Data Charter. Available online: https:/ / opendatacharter.net/principles/ (accessed on 20 April 2021).

22. World Bank. Readiness Assessment Tool. 2019. Available online: http://opendatatoolkit.worldbank.org/en/odra.html (accessed on 20 April 2021).

23. World Justice Project. Dimensions of the WJP Open Government Index. 2019. Available online: https://worldjusticeproject. org/our-work/wjp-rule-law-index/wjp-open-government-index/dimensions-wjp-open-government-index (accessed on 20 April 2021).

24. Access Info Europe. Open Government Standards. Available online: https://www.access-info.org/2015-01-22/opengovernment-standards (accessed on 20 April 2021).

25. Park, E.G.; Oh, W. Developing a Government Openness Index: The case of developing countries. Inf. Dev. 2019, 35, 121-134. [CrossRef]

26. Park, E.G.; Oh, W. Factors and their relationships in measuring the progress of open government. Aslib J. Inf. Manag. 2020, 72, 17-33. [CrossRef]

27. Open Government Partnership. Government Point of Contact Manual. 2016. Available online: https://www.opengovpartnership. org/sites/default/files/OGP_POC-Manual_2017_EN.pdf (accessed on 20 April 2021).

28. World Bank. Worldwide Governance Indicators. 2019. Available online: http://info.worldbank.org/governance/wgi/index. aspx\#home (accessed on 20 April 2021).

29. Transparency International. Corruption Perceptions Index 2020. 2021. Available online: http://www.transparency.org/research/ cpi/overview (accessed on 20 April 2021).

30. United Nations. E-Government Survey 2020: Digital Government in the Decade of Action for Sustainable Development with Addendum on COVID-19 Response E-Government Survey 2020. 2020. Available online: https:/ / publicadministration.un.org/ egovkb/Portals/egovkb/Documents/un/2020-Survey/2020\%20UN\%20E-Government\%20Survey\%20(Full\%20Report).pdf (accessed on 20 April 2021).

31. Economist Intelligence Unit. Democracy Index 2020: In Sickness and in Health? 2021. Available online: https:/ / www.eiu.com/ topic/democracy-index (accessed on 20 April 2021).

32. Freedom House. Freedom in the World 2020 a Leaderless Struggle for Democracy. 2021. Available online: https: / freedomhouse. org/report/freedom-world/2020/leaderless-struggle-democracy (accessed on 21 April 2021).

33. World Bank. World Development Indicators. 2021. Available online: http://data.worldbank.org/products/wdi (accessed on 20 April 2021).

34. Osberg, L.; Sharpe, A. How should we measure the 'economic' aspects of well-being? Rev. Income Wealth 2005, 51, 311-336. [CrossRef]

35. World Bank. World Bank Country and Lending Groups. Available online: https://datahelpdesk.worldbank.org/knowledgebase/ articles/906519-world-bank-country-and-lending-groups (accessed on 20 April 2021).

36. Kaiser, H.E. The application of electronic computers to factor analysis. Educ. Psychol. Meas. 1960, 20, 141-151. [CrossRef]

37. United Nations. E-Government Development Database. 2021. Available online: http://unpan3.un.org/egovkb/en-us/DataCenter (accessed on 20 April 2021).

38. Open Government Partnership. Independent Reporting Mechanism: Tunisia End-of-Term Report 2016-2018. 2021. Available online: https:/ /www.opengovpartnership.org/wp-content/uploads/2020/08/Tunisia_End-of-Term_Report_2016-2018_EN.pdf (accessed on 20 April 2021).

39. Open Government Partnership. Independent Reporting Mechanism (IRM): South Africa End-of-Term Report 2016-2018. 2021. Available online: https:/ /www.opengovpartnership.org/wp-content/uploads/2001/01/South-Africa_EOTR_2016-2018.pdf (accessed on 20 April 2021). 